\title{
ALTERNATIVE METHOD OF NON-DESTRUCTIVE TESTING FOR NUCLEAR POWER PLANT
}

\author{
Surin V.I. ${ }^{1}$, Alwaheba A.I. ${ }^{1 *}$, Beketov V.G ${ }^{2}$, and Abu Gazal A.A \\ ${ }^{1}$ National Research Nuclear University MEPhI \\ 115409, Kashirskoe shosse, 31 Moscow, Russia. \\ ${ }^{2}$ Volgodonsk Engineering Technical Institute-MEPhI \\ 73/94 Lenin St., Volgodonsk, Rostov region, 347360 Russia. \\ ${ }^{3}$ Jordan Atomic Energy Commission \\ Amman, Jordan, P. O. Box 70, Amman 11934, Jordan \\ *anas.kloub@jaec.gov.jo
}

\begin{abstract}
This study presents the results of electrophysical non-destructive testing of collectors welded joints to the body of steam generators PGV 1000M of the reactor WWER-1000. The studied steam generators located in the Resource Center of National Research Nuclear University MEPhI at the site of reactors construction factory "Atommash" in Volgodonsk city- Russia. The primary loop collector was welded to the body of steam generators PGV $1000 \mathrm{M}$ and the technical condition of welded joints was investigated by electrophysical non-destructive testing $(\mathrm{EPhT})$. In steam generators may appear corrosion and cracks due to corrosive environment and effect of stresses however, EPhT can detect early stages of cracks.

The study highlights the theoretical part of electrophysical diagnostics and control method, using modern mathematical signals analysis, and issues related to the practical implementation of EPhT in the factory. The novel alternative method of non-destructive testing can be used in diagnostic oil and gas pipelines, elements of complex technical structures and industrial equipment. It can be used in many industries where it is necessary to process control of the entire structure or its individual parts under operating conditions.

Based on control results, potentiograms were constructed for various structural levels of the diagnostic signal. The results of controlled welded joints in steam generators showed their satisfactory condition.
\end{abstract}

KEYWORDS: Scanning contact potentiometry, nondestructive testing, welded joints, Chromium-Nickeltitanium stainless Steel.

*Corresponding author: Anas Alwaheba, anas.kloub@jaec.gov.jo 


\section{INTRODUCTION}

Metal surface structure is extremely associated with electron behavior which is mainly depending on electron work function. Residual or applied stresses and defects lead to non-uniform distribution of surface Volta potential or electron work function $[1,2]$. Electron work function in solid state physics is defined as the difference in potential energy of an electron between the vacuum level and the Fermi level [3]. Contact potential difference was first introduced by Kelvin in 1898 [4]. Kelvin probe instrument is widely used to determine electron work function of metals and alloys surface, thus determine metal defects [5]. However, the main drawback of Kelvin probe is the inability of scanning tip to accurately trace the surface topography, which led to considerably unreliable results [6].

The intimate contact between scanning sensor and the sample surface play a vital role since the diagnostic signal is a result of low frequency waves of mechanical stresses emitted by defects in welded joint. These mechanical waves are spontaneously generated by a rapid release of energy within a material due to changes in defect's local stress and strain fields in metals. Therefore these waves can cause surface motion. These surface disturbances contain valuable information about location and characteristics of the defect $[7,8]$. On this basis scanning contact potentiometry (SCP) had been developed. SCP is considered a reliable nondestructive testing method $[9,10]$ where the relationship between deformational activity of the surface and electric properties of materials had studied thoroughly by Surin et al [11] they found out that growth of deformation subsequently lead to increase the number of spot of contact between sensor and the sample surface, therefore as result the amplitude of diagnostic signal considerably raised.

Application of nondestructive testing that can locate defects and their size is very important in nuclear power plant, since safe operation of nuclear power plants and their essential components, such as steam generators, is considered extreme priority task. Radiographic and ultrasonic are the most common two methods used in investigation steam generators. The advantage of radiography is that it provides a permanent visual record of the pattern of the degradation. The main disadvantage is that it is relatively insensitive to tight cracks [12]. On the other hand ultrasonic testing is used to find internal defects within weld or in metals being tested, though it has primary drawbacks limitation to materials above $6 \mathrm{~mm}$ thick and it is very dependent on skill of the operator [13]. SCP had overcome these drawbacks since it does not have thickness limitation and have high sensitivity. Moreover it can detect the early stage formation and growth of embryonic fatigue cracks in metals [14]. The aim of the present study is to assess the technical condition of steam generator welded joints in Atommash reactors factory in Volgodonsk city by electrophysical nondestructive testing (method of scanning contact potentiometry).

\section{EXPERIMENT AND THEORY:}

\subsection{Scanning contact potentiometry (SCP)}

The electrophysical method of nondestructive testing (SCP) is based on the principle of measuring the electrical potentials on the surface of the studied sample. If two metals A and B are brought into contact, there will be a potential difference, which is called the electric potential difference (Volt potential difference) [4]. Taking into account that real contact area between two metals is directly proportional to the load $[15,16]$. Therefore increasing load, lead to growth of the real contact area due to an increase in the number of contact spots with a slight increase in their size, which affects the magnitude and sign of the electric potential difference. Figure 1 clarifies the contact potentiometry principle. 


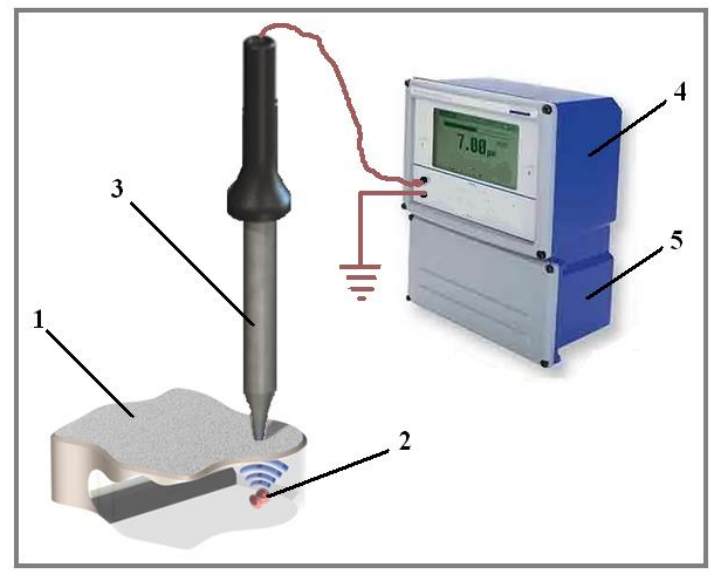

Figure 1.Signal measurement in electrophysical method: 1 -studied sample; 2-defect 3-sensor or transducer; 4-Measuring device (multimeter); 5- computer.

The waves of mechanical stresses in studied sample (1) caused by the defect (2) can cause surface motion which is converted into the electric potential difference by sensor (3). The electrical signals are amplified and measured by the multimeter(4), and transmitted to the computer (5).

Under load, waves of elastic and plastic deformation change the surface relief (waviness and roughness) which affects the electric double layer, the local electron density and the distribution of the electric potential on the surface. Due to the low energy of the generated mechanical waves, the signal has small amplitude and is shielded by the noise. In order to reduce the influence of noise component, signal processing program is used (figure 2). The figure shows the effect of increasing sample loading stages applied, on signal. Each increase in load leads to an increase in its amplitude.

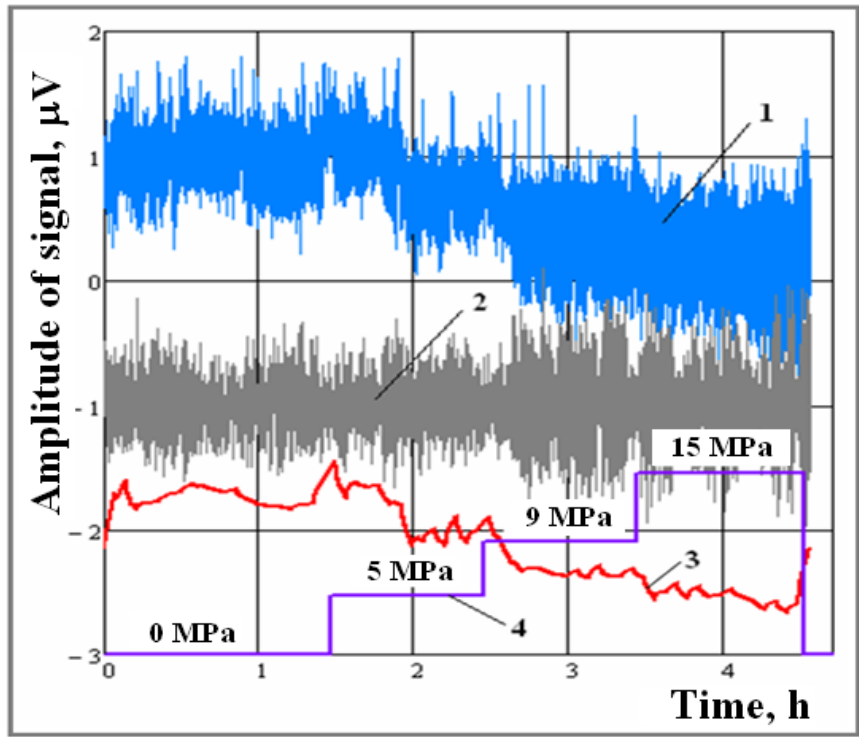

Figure 2.(1) Processing of the detected signal obtained by uniaxial tension of aluminum sample using a wavelet filter. (2) Noise component of the signal.(3)The signal without noise is shifted down from the noise axis by one unit. (4) Sample loading diagram. 
Electrical signal is characterized by spectral density, amplitude, time and amplitude-time distribution, as well as the average value and dispersion in a given time interval. These signal parameters are associated with their generating physical processes and convey information about studied object.

\subsection{Preparation of the stream generator pipe surface for conducting measurements}

Before carrying out EPhT measurements, the surface of welded joints of the steam generator and the controlled area were prepared in accordance with the requirements of Russian standard GOST 14782-86.

A layer of preservative grease was mechanically removed from the surface and then traces of rust were removed. After that, the surface was degreased using solvent №646 and wiped off. The cleaned surface was polished using sandpaper of different grits. Before each measurement, the sensor and the studied area were wiped with acetone moistened cotton.

Prior to the actual measurements, surface inspection of connected joint was carried out using hand lens and roughness was measured by VOGEL digital surface roughness measuring device SN A00212003015. At studied area, the surface roughness $\mathrm{R}_{\mathrm{a}}$ values ranged from 0.13 to $1.43 \mu \mathrm{m}$.

\subsection{The electro-physical non-destructive testing of stream generator pipe}

Evaluation of technical condition of welding in steam generators and detection of structural failures by EPhT method (scanning contact potentiometry method - SCP) was carried out in the Atommash reactors factory, Volgodonsk city, Russia. For carrying out measurements, a stationary sensor was placed on a prepared external surface of the steam generator away from the collector studied area. After that, mechanical scanning of welded joints by a scanning sensor was performed. Collector studied area were divided into eight tracks and potential values were recorded along these eight tracks. Four of them located to the left side of the welded joints (relative to the axis of symmetry of the welded joints) and four to the right. Measurements were performed by two sensors type, by points scanning using a pen sensor, and by using roller scanning sensor (EDSS-1RD). Manual point-by-point scanning of welded joints in steam generators was carried out for about $5 \mathrm{~mm}$ step along eight measuring tracks, the distance between each track and the next was $1.5 \mathrm{~mm}$. At each point of the welded joints, data was recorded using Agilent multimeter 34401A SN: MY 45040724. After scanning the entire track, procedures were repeated for the next track and so on up to eighth track. The average scanning speed for both sensors was about 10-20 $\mathrm{mm} / \mathrm{s}$. Sensors material was steel 12X18H10T (Chromium-Nickel-Titanium steel) used in this experiment.

\section{RESULTS:}

Potentiograms are constructed for different structural levels of the diagnostic signal (SLS, SLS $=$ $|\log | \varphi|| w h e r e ~ \varphi$ is function of diagnostic signal in time).

Classification of the detected structural inhomogeneities in welded joints was performed by comparing them with known structural inhomogeneities identified earlier on a specially prepared control welded joint (CWJ). For this purpose at the TEKHNOSCAN company in Volgodonsk city, Russia a special sample CWJ was prepared and carried out radiographic control. The CWJ sample was welded by manual arc welding of two austenitic steel $12 \mathrm{X} 18 \mathrm{H} 10 \mathrm{~T}$ plates. During welding process, welder purposely produced artificial discontinuities and introduced in CWJ different defects (edges offset, lack of fusion cutting, lack of root fusion and others). 
X-ray radiographic testing of the welded seam was carried out using equipment RAPAN M 200/100, SN 103326 in accordance with the methodology of Russian standard PNAE G-7-017-89, and then all detected structural inhomogeneities by EPhT were classified according to the results of radiographic control (figure 3). Figure 3 shows CWJ potentiogram for SLS=5.699. X-axis of the potentiogram displays the distance along the measuring tracks. The maximum $\mathrm{x}$ value corresponds to the length of weld joint. Y-axis indicates the track number in the measuring area. In the upper part of the figure located fragment of radiographic image of welding joint. In the radiographic image, obviously stand out tungsten inclusion defect in the form of light spot $(\mathrm{Ca})$ located to the left side of the fistula defect. The depth of tungsten inclusion, which is determined by ultrasonic testing method, is about $10 \mathrm{~mm}$. It is clearly visible burnThrough defect and the internal stresses around tungsten inclusions $(\mathrm{Ca})$.Using the obtained images of various defects on the potentiograms, with the corresponding values of the SLS, all defects identified in collector weld were classified.

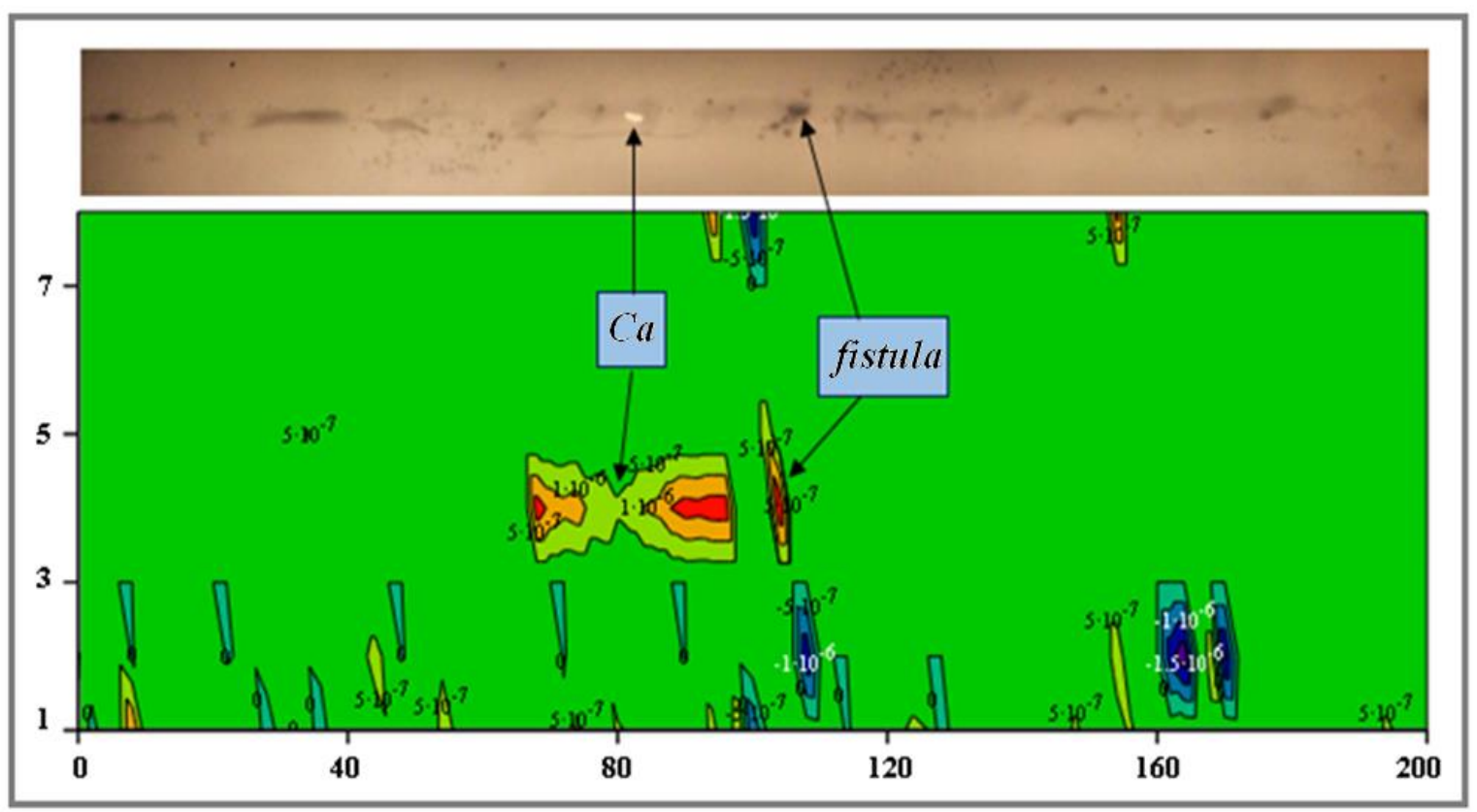

Figure 3. Radiographic image of welding joint in the upper part and potentiogram at SLS $=5.699$ in the bottom.

Figure 4 shows the surface potentiogram of welded joints in steam generator for low structural levels of the diagnostic signal (SLS=2) with a maximum amplitude of the signal $\varphi=0,01 \mathrm{~V}$. The upper part of the figure shows the spectra of time-frequency analysis (white arrows indicate the measuring tracks) and the change in the signal amplitude along the fifth, sixth and seventh tracks, respectively, from left to right. On these graphs, the amplitude in volts is plotted along the y axis, and the corresponding length of the welded joints in centimeters is plotted along the $\mathrm{x}$ axis. 


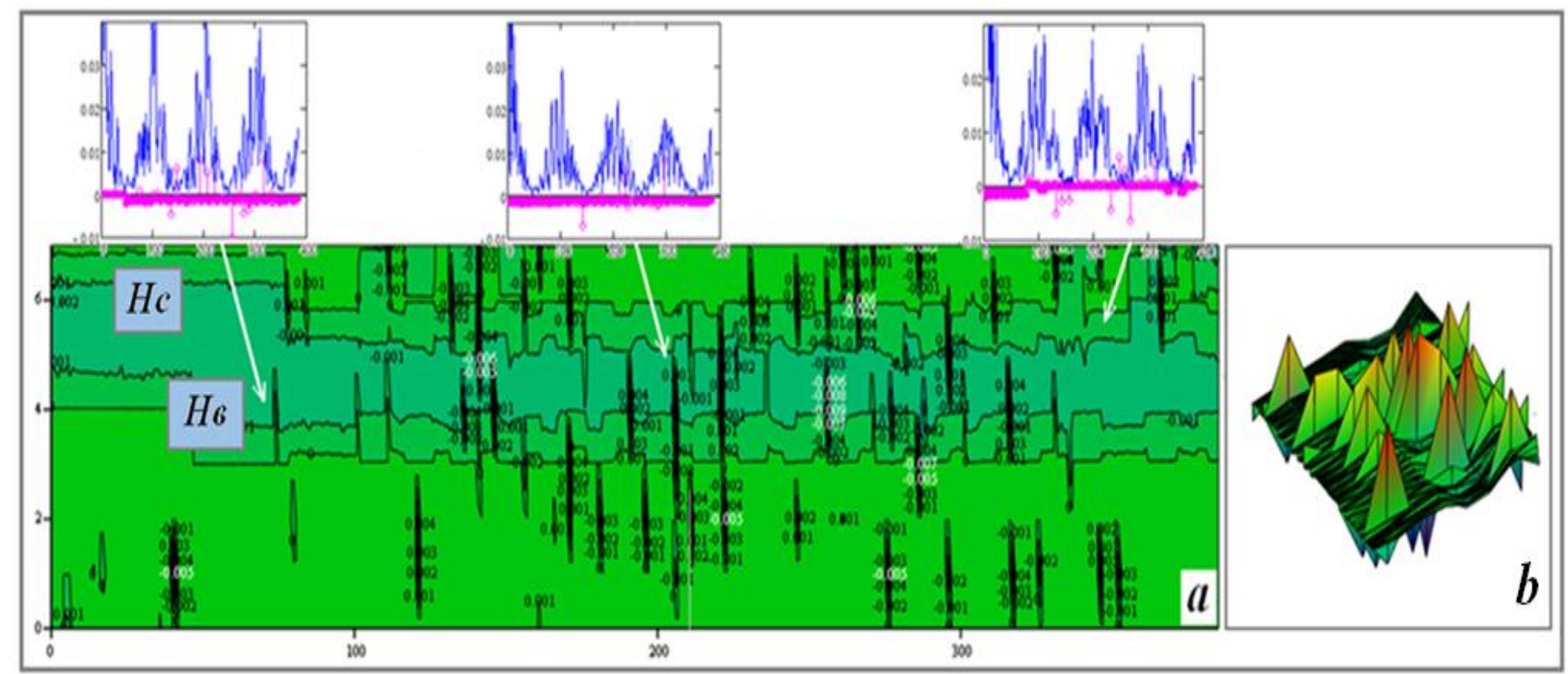

Figure 4. (a) Potentiogram ofsteam generator welding joints. (b) Three-dimensional representation of potentiogram. On all the graphs presented, the tracks counting starts from zero to seven.

At this structural level in figure 4(b), it is very obvious the most powerful amplitude structural inhomogeneities (red top peaks). In figure 4 (a), the non-fusion in the fifth track along the axis of the welded joint ("Hв") is clearly visible in form of a broad band of light green color. On the potentiogram it can also be seen the lack of penetration along the side ("Hc", top left) and numerous individual defects located randomly on the potentiogram. The results of time-frequency analysis confirm the presence of these micro-inhomogeneities.

More clearly, the non-fusion along the entire weld length appears on the potentiogram with SLS $=2.301$ (Fig. 5 a). The figure also shows the boundary between the fusion layers. At a higher resolution of SLS=2.959 (Fig.5 b), it can be seen that the non-fusion consists of separate fragments concentrated near the center line of the welded joints. In these zones, the effect of residual stresses leads to the formation of plastic deformation zones, concentrated in local volumes, which are effectively recorded by EPhT.

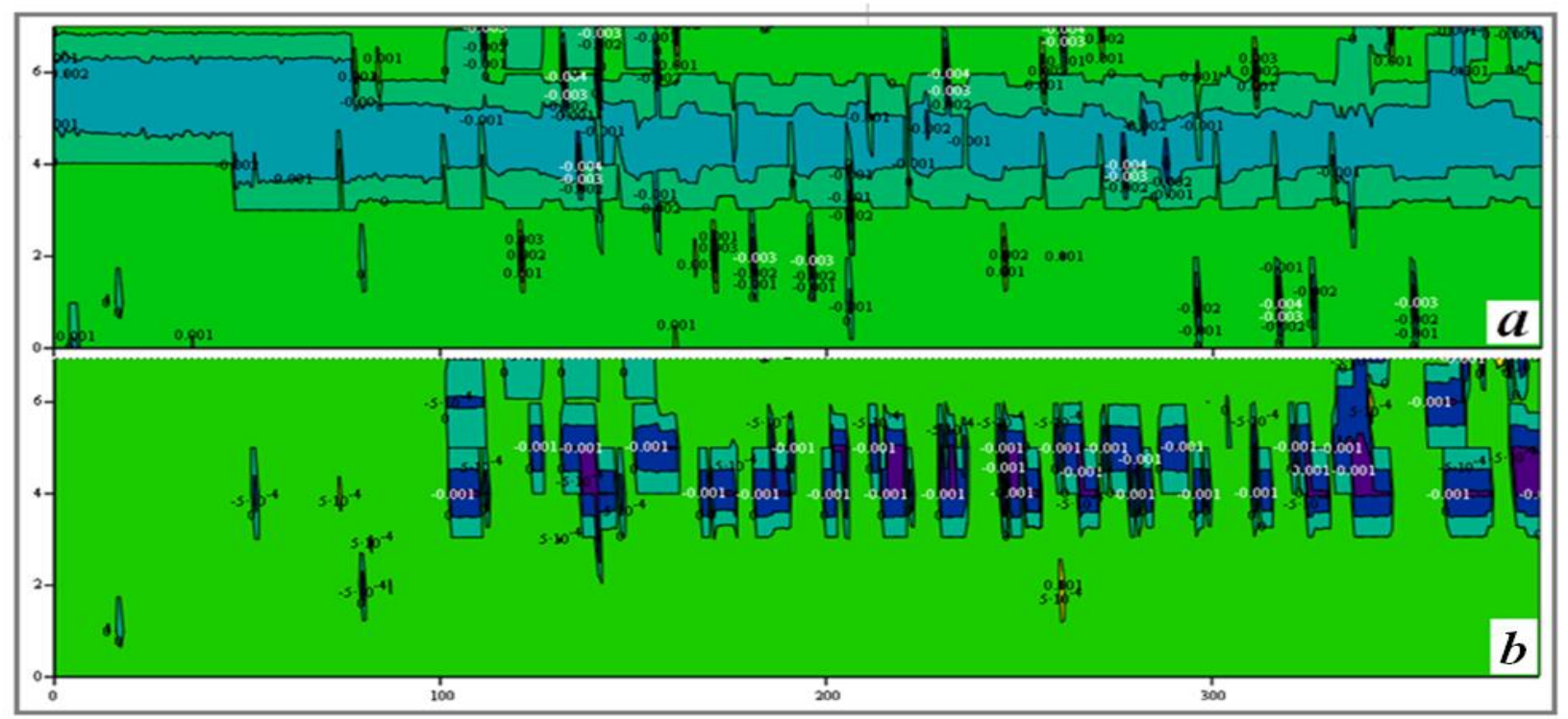

Figure 5. Collector welding joints potentiogram(a) SLS=2.301; (b) SLS=2.959. 
Figure 6 compares the results of using point by point sensor (Fig. $6 \mathrm{~b}$ ) and roller sensor EDSS-1RD(Fig. 6 a) for SLS = 3.097. Manual point-by-point scanning performed with measurement step of $5 \mathrm{~mm}$, allows to more effectively locating both single and extended defects. Defects have identical signal amplitude using both sensors are shown in white circle.

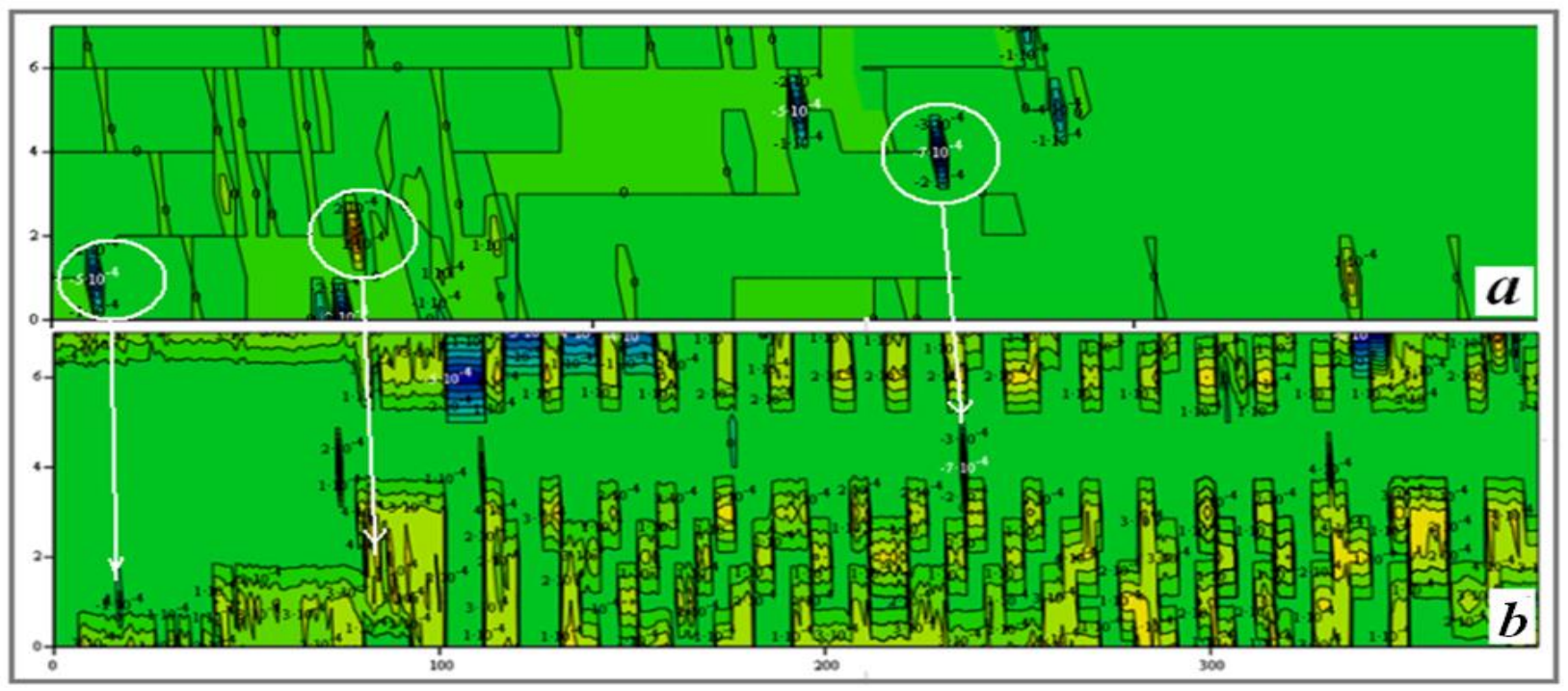

Figure 6. Potentiograms of manual scanning by (a) EDSS-1RD roller sensor, and (b) point-by-point pen sensor for $\operatorname{SLS}=\mathbf{3 . 0 9 7}$.

\section{CONCLUSIONS}

Electro-physical non-destructive testing using contact potentiometry was carried out in reactors factory Atommash in Volgodonsk city. Based on control results, potentiograms were constructed for various structural levels of the diagnostic signal. The classification of the detected structural inhomogeneities in welded joints was performed by comparing them with the known structural inhomogeneities identified earlier on a specially prepared control welded joint. The potentiogram analysis was performed by the method of sequential filtering of signals. The results of studying welding joints of steam generators showed their satisfactory condition.

\section{ACKNOWLEDGMENTS}

The work is supported by Russian Foundation Fundamental Research grant under the contract №19-0800266/19 from 10.01.2019.

\section{REFERENCES}

1. V.V. Levitin, O.L. Garin, V.K. Yatsenko, S.V. Loskutov. "On structural sensibility of work function". Vacuum,66, pp. 367-370 (2001).

2. Reza Rahemi, and Dongyang $\mathrm{Li}$, "Variation in electron work function with temperature and its effect on the Young's modulus of metals," Scriptamaterialia, 99, pp. 41-44 (2015).

3. C. Kittel, Introduction to Solid State Physics, Eighth edition, John Wiley \&Sons Inc(2005). 
4. L. Kelvin, "Contact electricity of metals". The London, Edinburgh, and Dublin Philosophical Magazine and Journal of Science, 46(278), pp.82-120 (1898).

5. A. Nazarov, and D. Thierry, "Application of Volta potential mapping to determine metal surface defects". Electrochimicaacta, 52, pp. 7689-7696 (2007).

6. T.H. Muster, and A.E. Hughes."Applications and Limitations of Scanning Kelvin Probe force microscopy for the Surface Analysis of Aluminum Alloys". Journal of the Electrochemical Society, 153(11), pp. B474-B485 (2006).

7. D. G. Eitzen, and H.N.G. Wadley, "Acoustic Emission: Establishing the Fundamentals."Journal of research of the National Bureau of Standards. 89(1), pp.75-100 (1984).

8. H.N.G. Wadley, C.B. Scruby, and J.H. Speake, " Acoustic emission for physical examination of metals." International Metals Reviews. 2, pp. 41-64 (1980).

9. V.I. Surin, Z.S. Volkova, R.A. Denisov, V.D. Motovilin, N.V. Rein. "Методы электрофизической диагностики и контроля реакторного оборудования [Methods of electrophysical diagnostics and control of reactor equipment]". Глобальная ядерная безопасность. 4(21), pp. 51-62 (2016) Russian.

10. V.I. Surin. "New potential for potentiometry." Nuclear Engineering International. 63(765), pp.30-32 (2018).

11. S.E. Arefinkina, R.A. Denisov, A.A. Morozov, V.I. Surin, "Relationship between deformational activity of the surface and electric properties of materials". Modern problems of theory of machines. North Charleston: Create Space. 4(1), pp. 177-183 (2016).

12. Strategy for Assessment of WWER Steam Generator Tube Integrity. Report prepared within the framework of the Coordinated Research Project on Verification of WWER Steam Generator Tube Integrity. IAEA-TECDOC-1577 (2007).

13. Steven E.Hughes, A Quick Guide to Welding and Weld Inspection, Woodhead Publishing limited (2009).

14. V.I.Surin, V.I. Zan'ko, A.P. Biryukov, "Diagnosis of the formation and growth of fatigue cracks in thin metal plates". Information technologies in designing and manufacturing.3, pp.71-77 (2013).

15. J. A. Greenwood and J. B. P. Williamson, "Contact of Nominally Flat Surfaces". Proceedings of the Royal Society of London. Series A, Mathematical and Physical Sciences. 295, pp.300-319 (1966).

16. J. A. Greenwood, "Constriction Resistance and the Real Area of Contact". British Journal of Applied Physics. 17, pp.1621-1632 (1966). 